\title{
SPECTRAL PHOTOELECTRIC SENSITIVITY OF SILVER SULPHIDE AND SEVERAL OTHER SUBSTANCES
}

\author{
By W. W. Coblentz and H. Kahler
}

\section{CONTENTS}

Page

I. Introductory statement. $\ldots \ldots \ldots \ldots \ldots \ldots \ldots \ldots \ldots \ldots \ldots \ldots \ldots \ldots \ldots \ldots \ldots \ldots \ldots, 23$ I

II. Apparatus and methods. . . . . . . . . . . . .

III. Photoelectrical sensitivity of silver sulphide.................. 234

r. Electrical polarization tests........................... 234

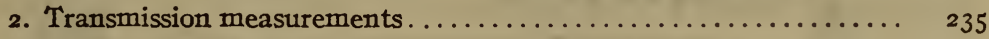

3. Variation of photoelectric current with time of exposure....... 236

4. Effect of intensity of radiation upon electrical conductivity ..... 237

5. Photoelectrical sensitivity of different parts of a crystal......... 238

6. Effect of temperature upon photoelectrical sensitivity......... $24 \mathrm{I}$

7. Effect of mechanical working upon spectral photoelectric sen-

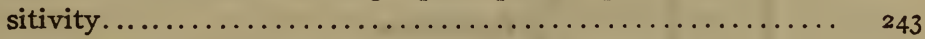

IV. Photoelectrical sensitivity of bismuthinite.................... 245

V. Photoelectrical sensitivity tests of various substances............. 246

I. Galena . . . . . . . . . . .

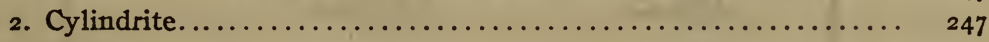

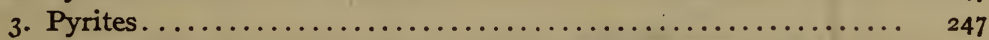

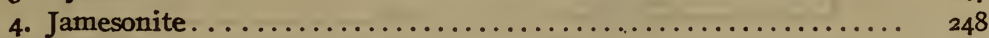

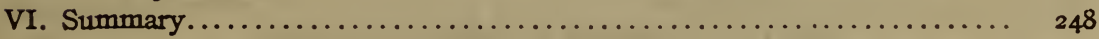

\section{INTRODUCTORY STATEMENT}

The preceding paper ${ }^{1}$ on this subject dealt with the spectral photoelectic sensitivity of molybdenite, under various conditions of operation, such as change in intensity of irradiation, change in temperature, etc. The present paper gives data of a similar investigation of various minerals, some of which had previously been tested $^{2}$ for photoelectrical sensitivity using heterogeneous thermal radiations. Further investigations should include a more detailed examination of some of the phenomena described in these foregoing papers.

As is well known, some substances exhibit luminescence only at low temperatures. It was, therefore, of interest to determine whether, similarly, some substances (for example, electrically conducting sulphides) might exhibit the phenomenon of photo- 
electrical sensitivity at low temperatures. In the preceding investigation of molybdenite, samples, which were quite insensitive photoelectrically at room temperatures, became fairly sensitive when cooled to low temperatures.

\section{APPARATUS AND METHODS}

The spectroradiometric apparatus was essentially the same as that used in a similar investigation of the photoelectrical sensitivity of molybdenite to which reference should be made for a description of the general experimental procedure. ${ }^{3}$ Several minor changes in experimentation had to be introduced in view

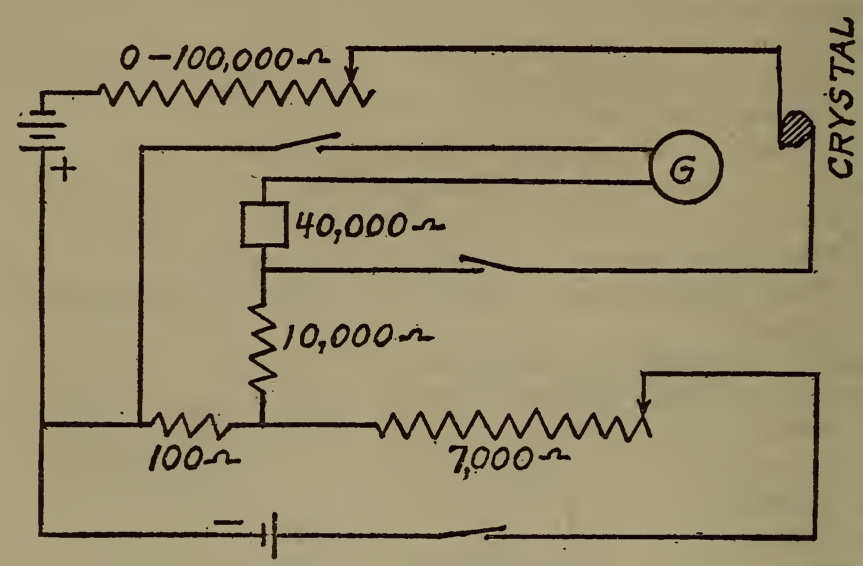

FIG. I.-Arrangement of electrical connections

of the low electrical resistance and the low photoelectrical sensitivity of the material examined.

In order to balance the large dark current which obtained in these minerals, at room temperature, current from an auxiliary battery was passed in the opposite direction through the galvanometer, $G$, as shown in Fig. I. The preliminary electrical adjustments were made by using a d'Arsonval galvanometer, which was then replaced by an ironclad Thomson galvanometer. ${ }^{4}$ This was necessary in order to be able to measure the small photoelectric currents induced in most of the crystals. This appears to be the first time that a sensitive Thomson galvanometer has been used in this type of photoelectric work. Usually the photoelectric currents were sufficiently large so that a resistance of ro 000 to 20000 ohms was kept in series with the galvanometer. 
At low temperatures the dark current through the sample under examination was usually so low that it was unnecessary to balance its effect by means of the auxiliary battery.

The material examined was (I) the natural crystalline mineral, Acanthite, and (2) a laboratory preparation, made by G. W. Vinal', and hammered into a thin $(0.05 \mathrm{~mm})$ homogeneous flexible strip. This is sample No. IV in the present investigation. The crystalline material, Acanthite, $\mathrm{Ag}_{2} \mathrm{~S}$ was obtained from the United States National Museum. Samples Nos. I and II came from Freiberg, Saxony. Samples Nos. III and V (U. S. Nat. Mus. No. 85162) came from Zastecas, Mexico. Their dimensions ranged from I 2 to $18 \mathrm{~mm}$ in length and from 2 to $4 \mathrm{~mm}$ in width. Their ends were filed flat and clamped securely between copper washers by means of small brass screws. This provided excellent electrodes. This combination was then mounted securely upon a fiber block and the crystal was covered with cardboard with a slit cut into it to admit radiation upon a certain part of the sample under examination.

In the first tests the copper lead wires were attached by heating the wires to their melting point, and then touching them to the acanthite crystal. "This made a good juncture, which, however, deteriorated very rapidly after passing electric current for a short time. This did not have any effect upon the spectral photoelectric sensitivity curve, as found by actual observation; but the method had to be abandoned because of the gradual increase in resistance as a result of electrolytic action at the juncture. In one case this difficulty did not manifest itself until the following day, although the crystal had not been attached to the battery for more than a half hour on the preceding day.

The preliminary observations were always extended to about $3 \mu$. However, none of the substances examined were photoelectrically sensitive beyond $2 \mu$. Because of the low intrinsic photoelectrical sensitivity of silver sulphide, the intensity of the radiation stimulus used throughout this investigation was nine times that used in the investigation of molybdenite. At this intensity the equal energy spectrum-that is, the photoelectrical observations-began at $0.75 \mu$ (see Fig. 6, $E=9$ ). But tests made with the intensity $E=I$, which was used on molybdenite, showed that the spectral photoelectric sensitivity of silver sulphide is much less in the yellow than in the red, and in succeeding parts of the spectrum. 


\section{PHOTOELECTRICAL SENSITIVITY OF SILVER SULPHIDE}

In the beginning of this investigation it was observed that silver sulphide had unusual properties not possessed by the substances previously examined. It was observed that the maximum galvanometer deflection was attained in a few seconds, after which the photoelectrical activity decreased to perhaps only one-fourth its original effect. There seemed to be a large "fatigue," " though previous writers have not described the phenomenon very clearly, if at all.

Aside from this "fatigue," considerable difficulty was experienced in making observations at room temperature. After a

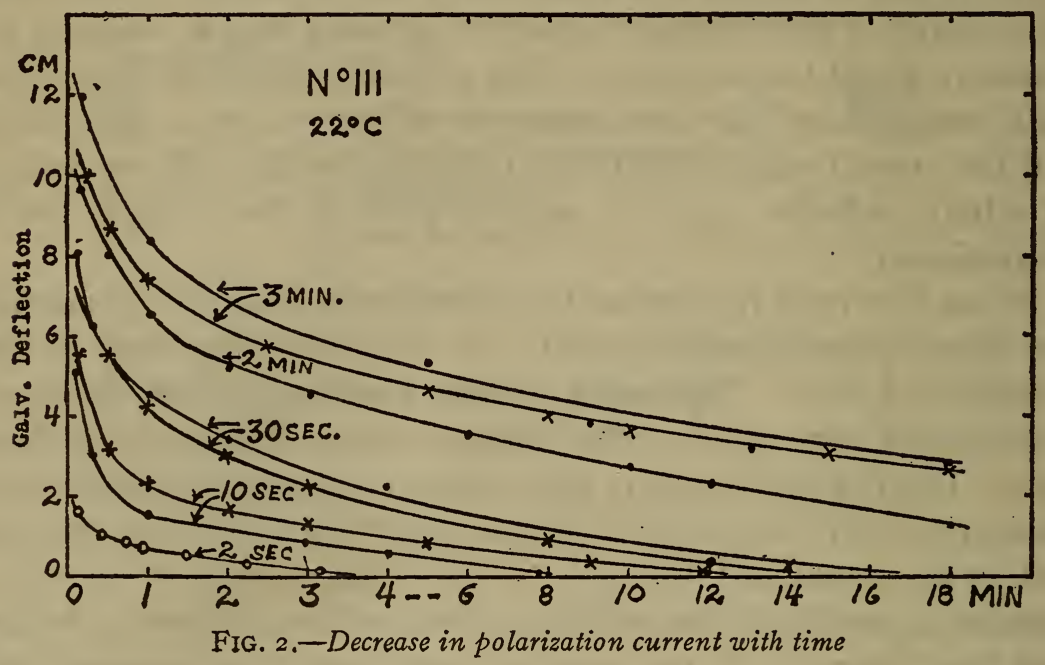

short time the galvanometer would become very unsteady, though on reversing the current through the crystal this unsteadiness would sometimes be eliminated for a short time. Evidently electrolytic action was present and one of the first tests made was on the electrolytic action induced in the crystal.

In order to reduce this unsteadiness it was, therefore, necessary to pass current through the crystal only when making observations. In order to diminish the effect of fatigue the maximum throw of the galvanometer, which was attained in about three seconds, was observed.

\section{ELECTRICAL POLARIZATION TESTS}

The electrolytic polarization voltage developed in the crystal was tested very simply by means of the Thomson galvanometer having a single swing of about 2.5 seconds. By means of a double- 
throw switch, the crystal was connected for a short time (two seconds to three minutes) with a 2-volt storage battery, then quickly joined to the galvanometer. This would produce a large deflection, which would gradually return to the zero reading. As shown in Fig. 2, passing current through the crystal for two seconds, and then connecting to the galvanometer, would produce a deflection of $2 \mathrm{~cm}$, while passing the current for three minutes would produce a deflection of about $12 \mathrm{~cm}$. In other words, as shown in Fig. 3 (which gives the maximum deflection, from Fig. 2) the polarization voltage increases very rapidly during the first few seconds, then gradually assumes a constant value.

Observations were made of the polarization produced when the crystal was kept in the dark (Fig. 2, dots, •••) and when it

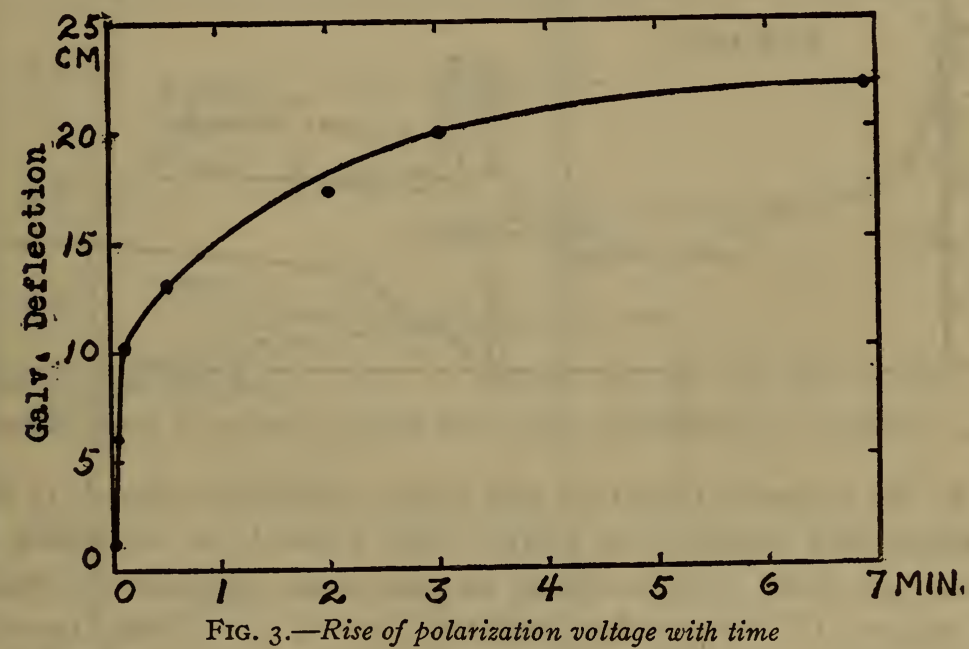

was illuminated (Fig. 2, crosses, $\times \times \times$ ). The results show that with this rather crude method of observation no marked difference was observed in the polarization current.

\section{TRANSMISSION MEASUREMENTS}

In view of the interest in the question whether there is any connection between absorption and photoelectrical sensitivity, transmission measurements were made on a thin sample of silver sulphide prepared by Mr. Vinal. The sample examined was a thin flexible plate about $\mathrm{r} 5$ by 8 by $0.05 \mathrm{~mm}$. Several examinations were made, the final test being made with the plate of silver sulphide placed directly over the spectrometer slit. The examination extended from $0.6 \mu$ to $4 \mu$. Throughout this region of the spectrum the sample appeared to be entirely opaque. 
3. VARIATION OF PHOTOELECTRIC CURRENT WITH TIME OF EXPOSURE

In the paper on molybdenite it was shown that for wave lengths greater than $0.75 \mu$ the time of exposure for equilibrium varies from 30 seconds to several minutes and that the time for recovery is twice the exposure time.

At room temperature silver sulphide behaves in an entirely different manner. As shown in curve $A$, Fig. 4, on exposing the crystal to radiation, the maximum galvanometer deflection is attained in 3 to 5 seconds after which the photoelectric current gradually decreases, so that after 15 minutes' exposure the deflection is perhaps only one-seventh its maximum value. If the light stimulus is then removed, the galvanometer gives a deflec-

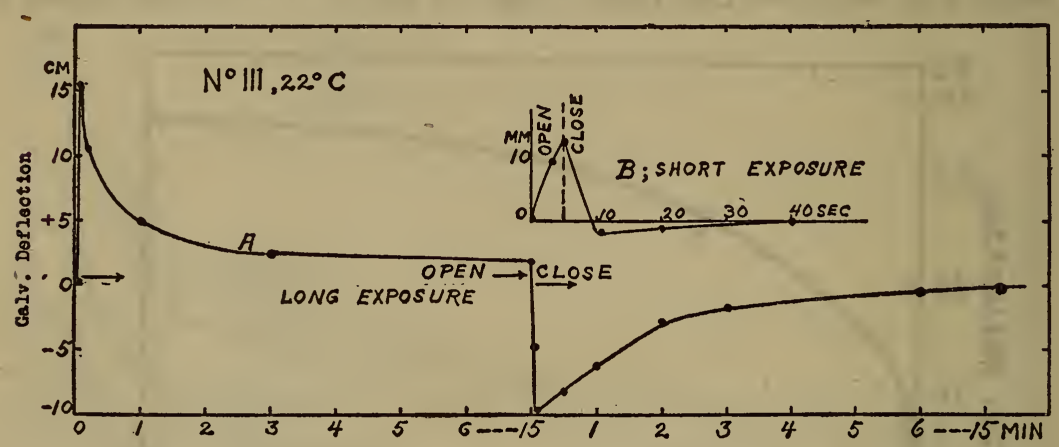

FIG. 4.-Variation of photoelectric current with time of exposure at room temperature

tion in the opposite direction and finally returns to zero. It was, therefore, not possible to subject the crystal to unlimited exposure (at room temperature) as was done with molybdenite. The system of observation adopted for all the herein recorded measurements, at room temperature, was to expose the crystal for about 5 seconds, read the maximum throw, and then close the shutter. The galvanometer deflection then returned to its zero position, as shown in curve $B$ of Fig. 4 . It is therefore quite probable that, if unlimited exposure could have been used, the sensitivity maxima would occur at slightly longer wave lengths than here recorded. At low temperatures this electrolytic action disappears, and the time-response curves, as shown in Fig. 5, are somewhat similar to those observed on molybdenite with this difference, that the time for recovery is the same as the time of response. 
4. EFFECT OF INTENSITY OF RADIATION UPON ELECTRICAL CONDUCTIVITY

The effect produced upon the spectral photoelectric sensitivity of silver sulphide (Acanthite, sample No. I) on varying the intensity of the exciting radiation is shown in Fig. 6. Increasing the intensity nine times has a marked effect in increasing the

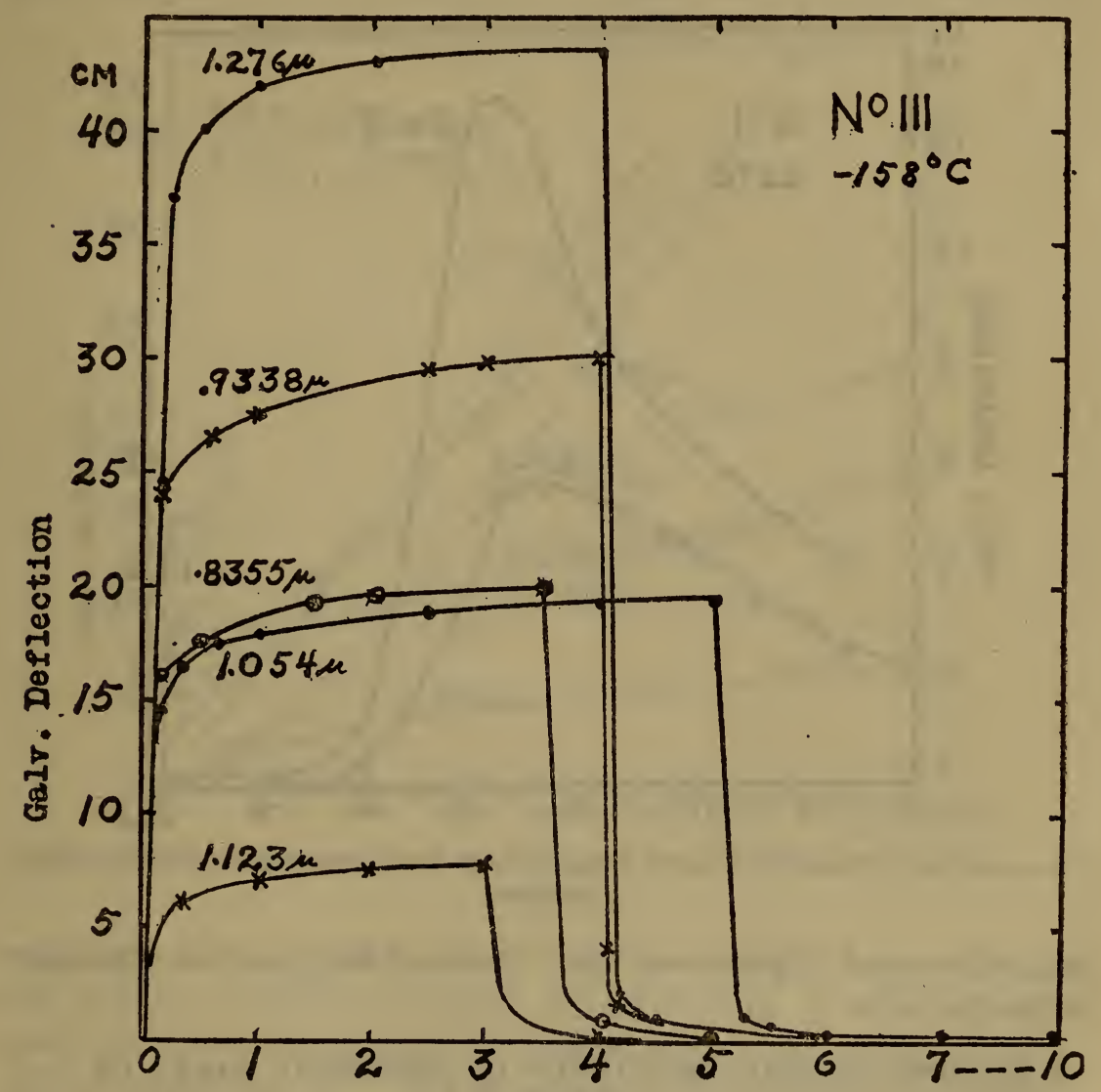

FIG. 5.-Variation of photoelectric current in silver sulphide with time of exposure, at low temperatures

photoelectrical sensitivity in the long wave lengths, as previously observed in molybdenite.

In Fig. 7, a series of isochromatic curves are given, showing the effect of intensity as well as temperature upon the photoelectric response. At $-158^{\circ} \mathrm{C}$. the effect of electrolytic action is absent and it was possible to expose the sample to radiation until photoelectric equilibrium was attained. The response curves for wave lengths $\lambda=\mathrm{I} .054 \mu$ and $\mathrm{I} .357 \mu$ are entirely different from those 
obtained at room temperature. But they verify the observations at room temperature showing that with increasing intensity the photoelectrical sensitivity shifts toward the long wave lengths. For example, the ratio of galvanometer deflections at $\lambda=1.054 \mu$, for $E=5$ and $E=20$ (square root of the ratio of these intensities $=2$ ) is 3 while for $\lambda=1.357 \mu$ this ratio is 6 . Furthermore, the

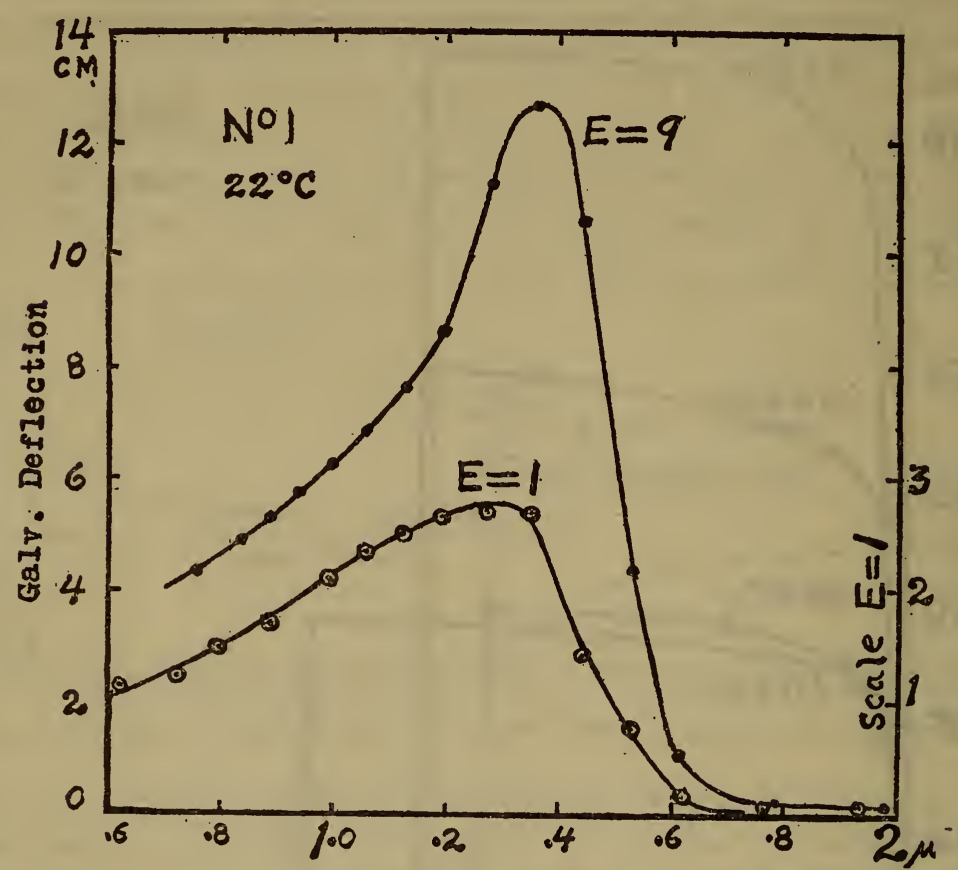

FIG. 6.-Effect of intensity of energy stimulus upon the spectral photoelectric sensitivity of acanthite

much discussed "square root law" does not hold, as was observed in molybdenite.

\section{PHOTOELECTRICAL SENSITIVITY OF DIFFERENT PARTS OF A CRYSTAL}

In the preceding paper it was shown that different parts of a sample of molybdenite exhibit markedly different photoelectrical sensitivity curves, and attention was called to the possibility of this phenomenon being ascribable to the presence of different kinds of sulphides of molybdenum.

The spectral photoelectric sensitivity curve of acanthite $\left(\mathrm{Ag}_{2} \mathrm{~S}\right)$ at room temperature is not unlike that of selenium except that its maximum occurs much farther in the infra-red; at $\lambda=\mathrm{I} .35 \mu$. There is a region of high sensitivity at $0.6 \mu$ to I $\mu$ (see Fig. 6) 
similar to the high sensitivity of selenium, in the visible spectrum. The sensitivity in this region, relative to that at the maximum, varies somewhat for different parts of the crystal, but it is not very conspicuous in comparison with the observations on molybdenite.

In Fig. 8 curve $A$ gives the photoelectrical sensitivity of the front (smooth) side of sample No. I, while curve $B$ illustrates the

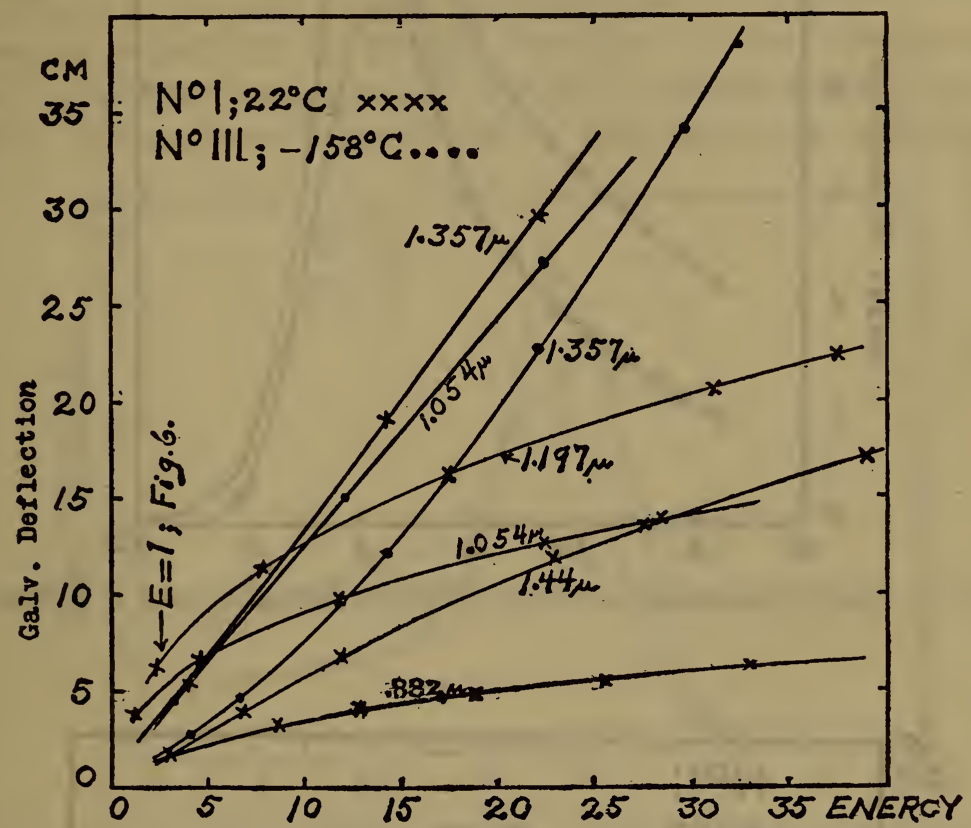

FIG. 7.-Effect of intensity of energy stimulus upon the spectral photoelectric response of acanthite

sensitivity of the opposite side of this crystal which side was rough and uneven. Similarly, curves $A$ and $B$, Fig. 9, illustrate the spectral photoelectric sensitivity respectively of the front and rear side of sample No. II. In Fig. ro curve $A$ illustrates the photoelectrical sensitivity of the smooth (front) side, and curve $B$ the rear (rough) side of sample No. III, which came from Zastecas, Mexico. Curve $A$ in Fig. I 3 illustrates the sensitivity of a similar sample, No. V. With the exception of the latter, all these spectral photoelectrical sensitivity curves are very similar, considering the fact that in all cases the observations are somewhat affected by the electrolytic action. The observations at low temperatures confirm these data, showing a marked similarity in the spectral photoelectric sensitivity curves of the natural (unworked) crystal of acanthite. 


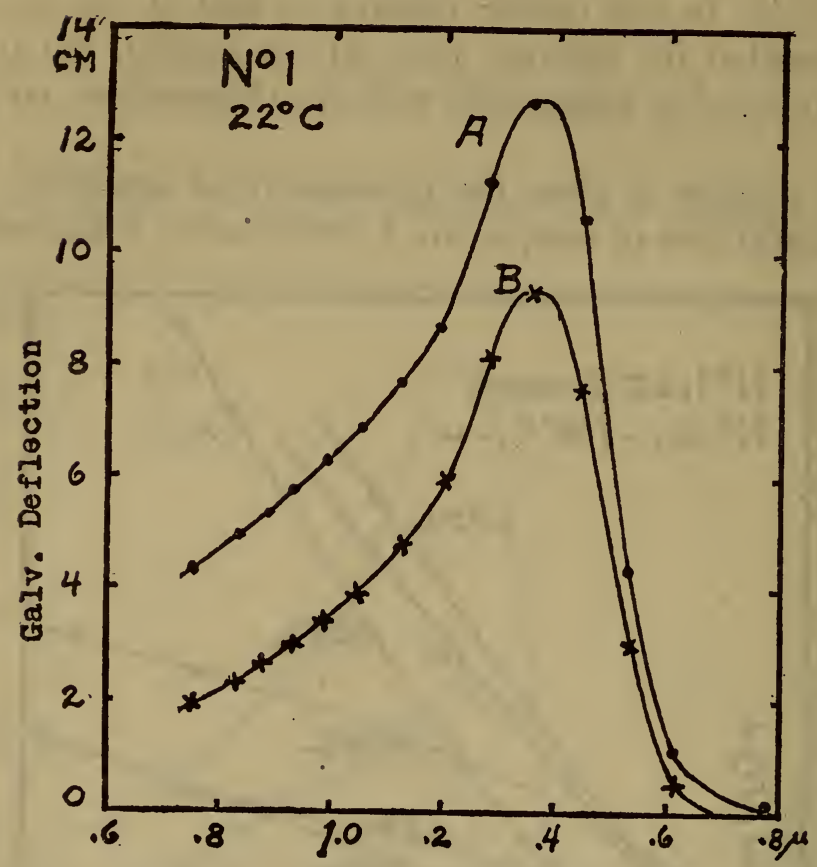

FIG. 8.-Spectral photoelectric sensitivity of different parts of a crystal of acanthite

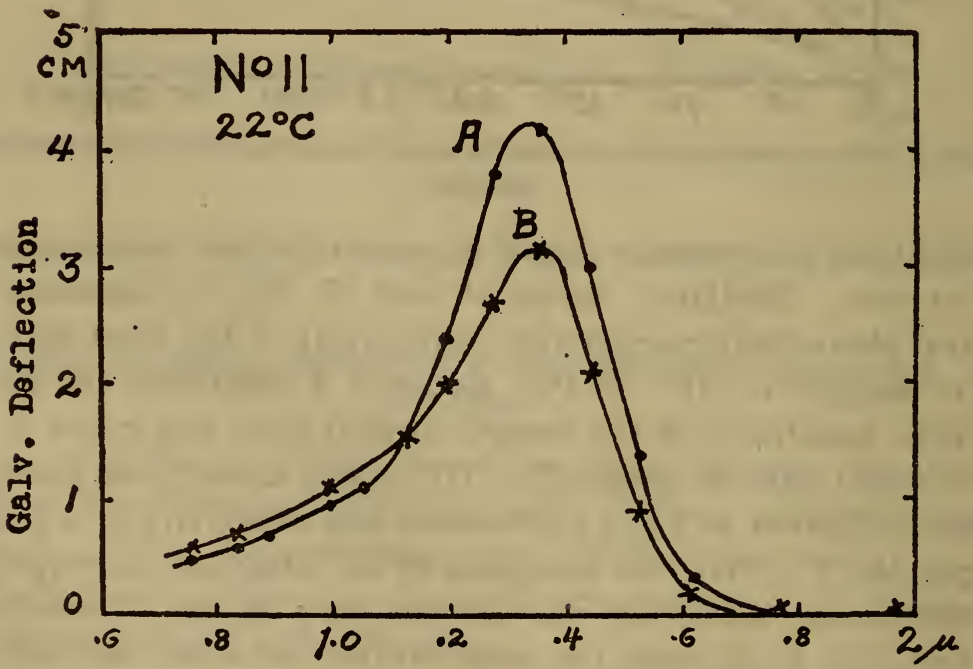

FIG. 9.-Photoelectrical sensitivity of different parts of a crystal of acanthite 


\section{EFFECT OF TEMPERATURE UPON PHOTOELECTRICAL SENSITIVITY}

As already mentioned, disturbances from electrolytic action ceases at low temperatures, and it is possible to obtain spectral photoelectric sensitivity curves for unlimited time exposures.

The effect of lowering the temperature to $-15^{\circ} \mathrm{C}$ is to produce a sharp symmetrical band of spectral photoelectric sensitivity with a single maximum at $\mathrm{I} .2 \mu$. This is illustrated in Figs. II, I2, and I3, for samples Nos. II, III, and V. The intrinsic sensitivity is greatly increased at low temperatures, but no attempt was made to obtain a comparison of the sensitivity at these two temperatures as was done with molybdenite.

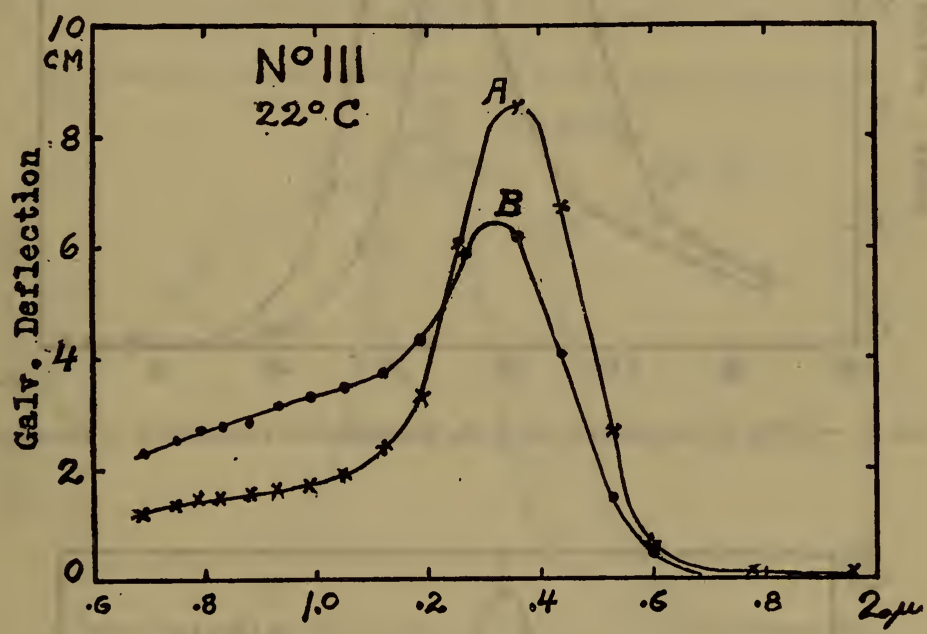

FIG. Io.-Photoelectrical sensitivity of different parts of a crystal of silver sulphide (acanthite)

In Fig. I I the deflections for $-158^{\circ} \mathrm{C}$ were four times the scale indicated. In Figs. $\mathrm{I} 2$ and $\mathrm{I} 3$ the observations at room temperatures were one-tenth the scale indicated.

It is of interest to record that the temperature coefficient of resistance of silver sulphide is high, so that at $-158^{\circ} \mathrm{C}$ the hammered material is practically an insulator, and it is possible to connect a sensitive $\left(i=3 \times 10^{-10}\right.$ ampere) Thomson galvanometer directly through a crystal and a battery of several volts. For example, sample No. IV (Fig. I6), which had a resistance of 3 ohms at $22^{\circ} \mathrm{C}$, was joined directly through the galvanometer and 2 volts, causing a deflection of only $15 \mathrm{~mm}$. The resistance was increased about 100000000 times that at room temperature. Similarly, sample No. I, after rehammering, was joined through 


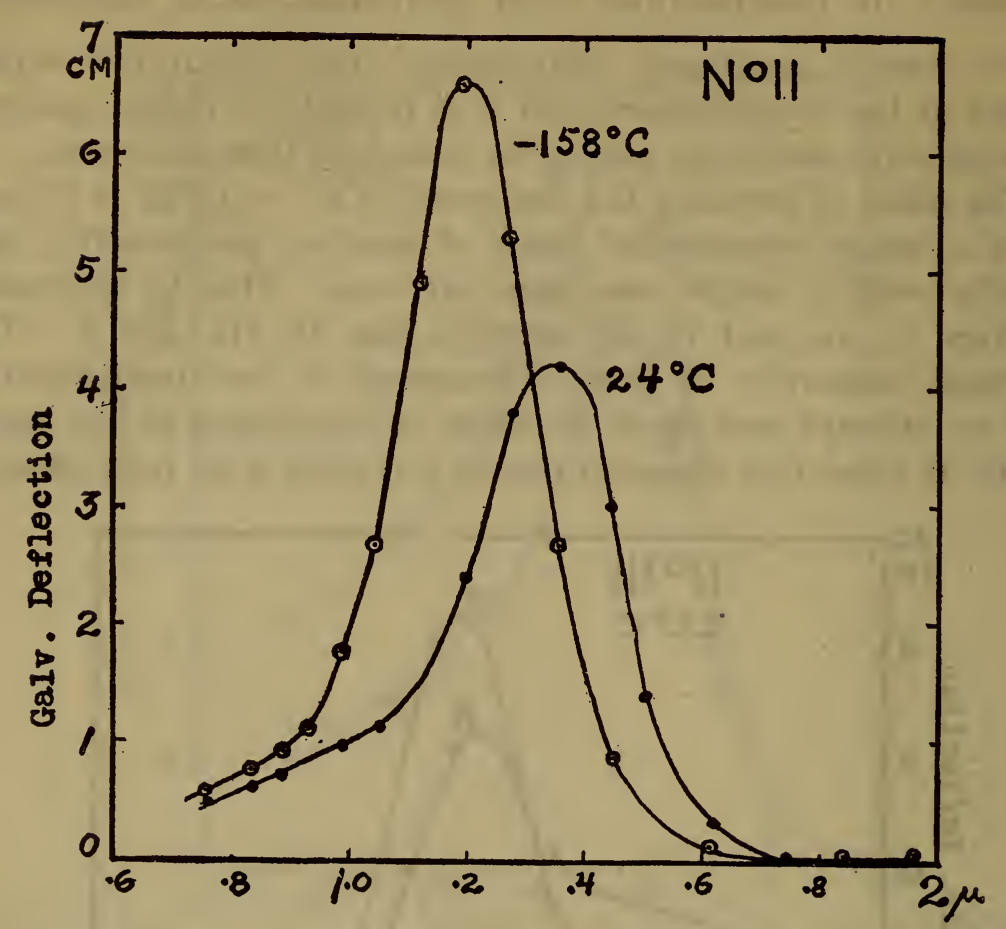

FIG. II.-Effect of temperature upon the photoelectrical sensitivity of acanthite

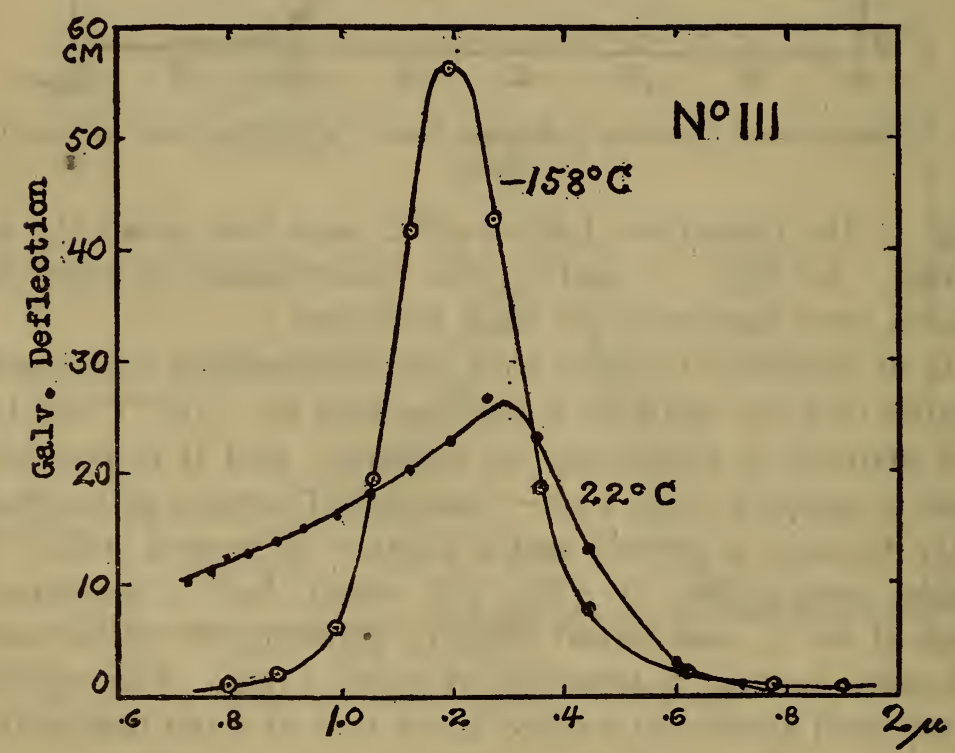

FIG. 12.- Effect of temperature upon the spectral photoelectric sensitivity of acanthite 
I 9.6 volts to the galvanometer, causing a (dark current) deflection of only $17 \mathrm{~mm}$. In other words, its resistance was several hundred meg-ohms. That this is not a result of poor contact at the electrodes was shown by increase in resistance with hammering; that is, decrease in thickness of the material.

\section{EFFECT OF MECHANICAL WORKING UPON SPECTRAL PHOTOELECTRIC SENSITIVITY}

In previous communications ${ }^{7}$ attention was called to observations on a change in spectral photoelectric sensitivity as a result of hammering and otherwise mechanically working the crystal. The hammered material is less sensitive photoelectri-

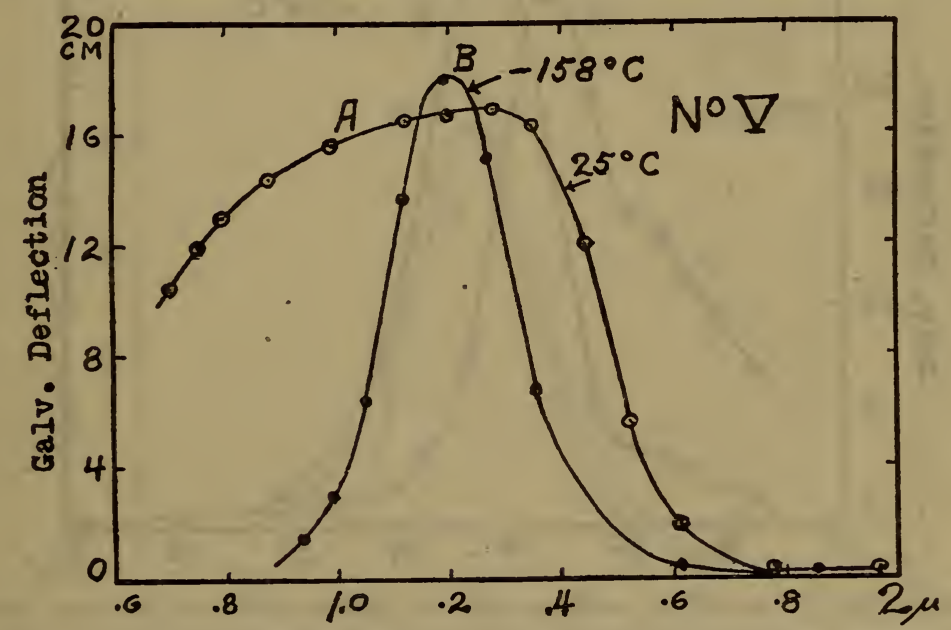

FIG. 13.-Effect of temperature upon the photoelectric sensitivity of acanthite

cally than the crystalline material. For this reason, as well as difficulties in observing at room temperature, the photoelectrical measurements were made at low temperatures, $-158^{\circ} \mathrm{C}$. Through an oversight the sensitivity of sample No. I was not determined before hammering. However, judging from the similarity in behavior of all the other samples (see Figs. II, I2, and 13 ), it is not unreasonable to suppose that the maximum of the unhammered sample occurs at 1.2 $\mu$. After subjecting this crystal to hammering, the spectral photoelectric sensitivity curve appears complex with maxima at $0.95 \mu$ and I.I $2 \mu$, as illustrated in curve $A$, Fig. I4. On further hammering the crystal it was reduced to a thin, pliable, noncrystalline lamina (about $0.2 \mathrm{~mm}$ in thickness) having a highly metallic luster. As shown 
in curve $B$, Fig. I4, the sensitivity curve is quite symmetrical with a maximum at $1.23 \mu$, which is somewhat greater than the maximum I. $20 \mu$, observed in the crystalline state (see Figs. II, I2, and I3.)

In curve $A$, Fig. I5, is illustrated the sensitivity curve of sample No. III, which before hammering has a maximum at I.I $\mu$. After hammering, curve $B$, the maximum sensitivity appears slightly shifted, to about I.2 2 . This sample was very

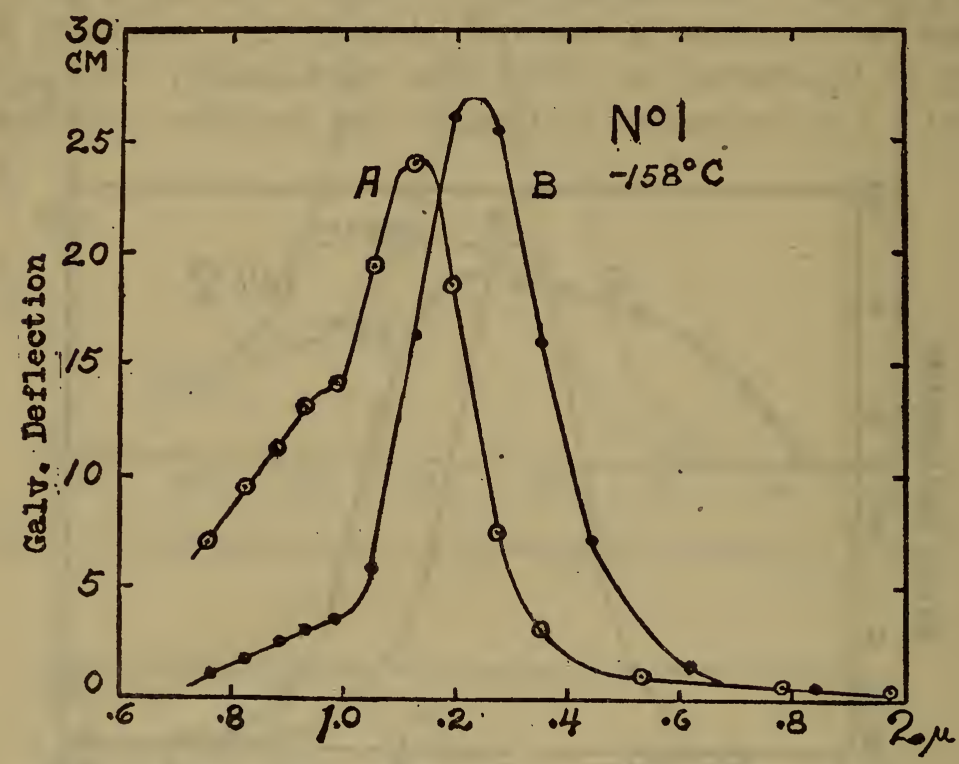

Fig. I4.-Effect of mechanical working upon the photoelectrical sensitivity of acanthite

brittle, which condition did not permit hammering the material into a pliable noncrystalline plate.

In Fig. I 6 is shown the spectral photoelectric sensitivity curve of a laboratory preparation of silver sulphide by G. W. Vinal. ${ }^{8}$ It consisted of a thin, flexible, noncrystalline plate, size about I 5 by 3 by $0.05 \mathrm{~mm}$.

As shown in the lower curve of Fig. 16 , at $25^{\circ} \mathrm{C}$, this material did not show photoelectrical sensitivity for the spectral radiation intensities applied. However, for these same intensities, applied at $-158^{\circ} \mathrm{C}$, the intrinsic sensitivity is high, and the spectral photoelectric sensitivity curve is quite symmetrical, with a maximum at $\mathrm{r} .05 \mu$. This maximum is at a much shorter wave length than observed in the natural mineral acanthite. 
From the data herewith presented, it appears that the spectral photoelectrical sensitivity curve of silver sulphide is influenced by the physical condition of the mineral. It appears profitable to continue this investigation of the natural mineral as well as the artificial product after subjecting it to heat treatment, mechanical working, etc.

\section{PHOTOELECTRICAL SENSITIVITY OF BISMUTHINITE}

In a previous investigation ${ }^{9}$ it was shown that crystals of bismuthinite, $\mathrm{Bi}_{2} \mathrm{~S}_{3}$, are sensitive in spots, often localized at the intergrowth of two bundles of acicular crystals. The sample (U. S. Nat. Mus. No. 14046, from Cornwall, England) used in the

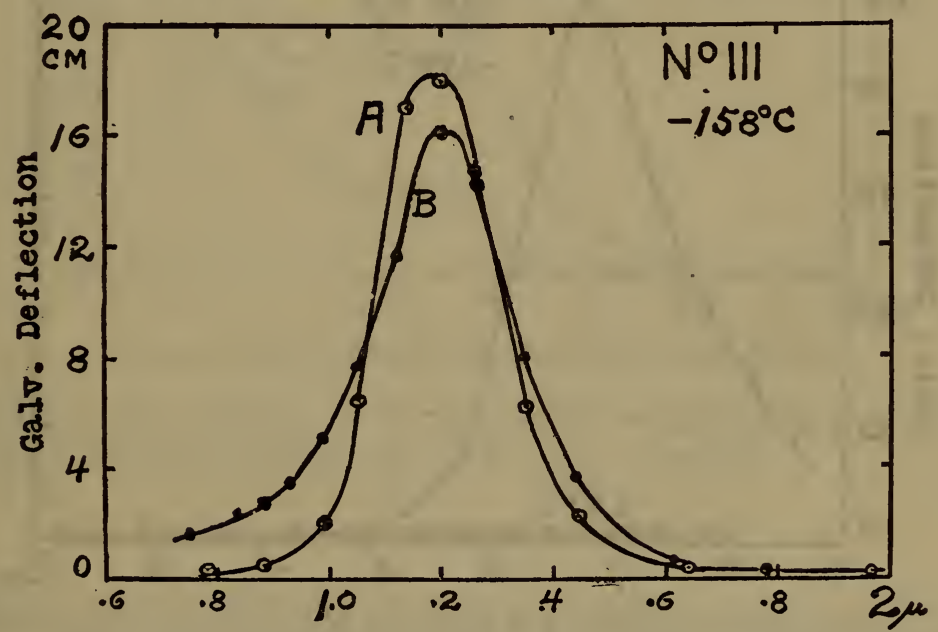

FIG. 15.-Effect of mechanical working upon the spectral photoelectric sensitivity of acanthite

present examination was a straight rod of fibrous material about Io by 1.5 by $0.7 \mathrm{~mm}$. The electrodes, which were of No. 30 copper, were attached to the crystal by means of solder. As described in the paper, just cited, the solder on cooling and solidifying holds the crystals very securely to the copper wires. Tests were made showing that dental amalgam is an excellent means for attaching wires to substances that will not take solder, but this research was terminated before this procedure was adopted as a general method of making electrical connections.

Tests made at room temperatures showed that the highest spectral intensities attainable were not sufficient to obtain a reliable photoelectrical sensitivity curve. Measurements were there- 
fore made only when the bismuthinite was at low temperatures, $-166^{\circ} \mathrm{C}$. But even at this temperature the galvanometer was very unsteady, owing to lack of proper temperature control of the sample, the resistance of which changes rapidly with temperature. A change of a hundredth of a degree in temperature is sufficient to cause a drift in the galvanometer reading. To eliminate the effect of drift in the galvanometer reading, the ballistic throw was used. In this manner the spectral photoelectric sensitivity curve, $B$, Fig. $\mathrm{I} 7$, was obtained. It represents the average of a great many readings, and shows that there are two sensitivity maxima, at about $0.64 \mu$ and $\mathrm{r} .08 \mu$, respectively. Curve $A$ illus-

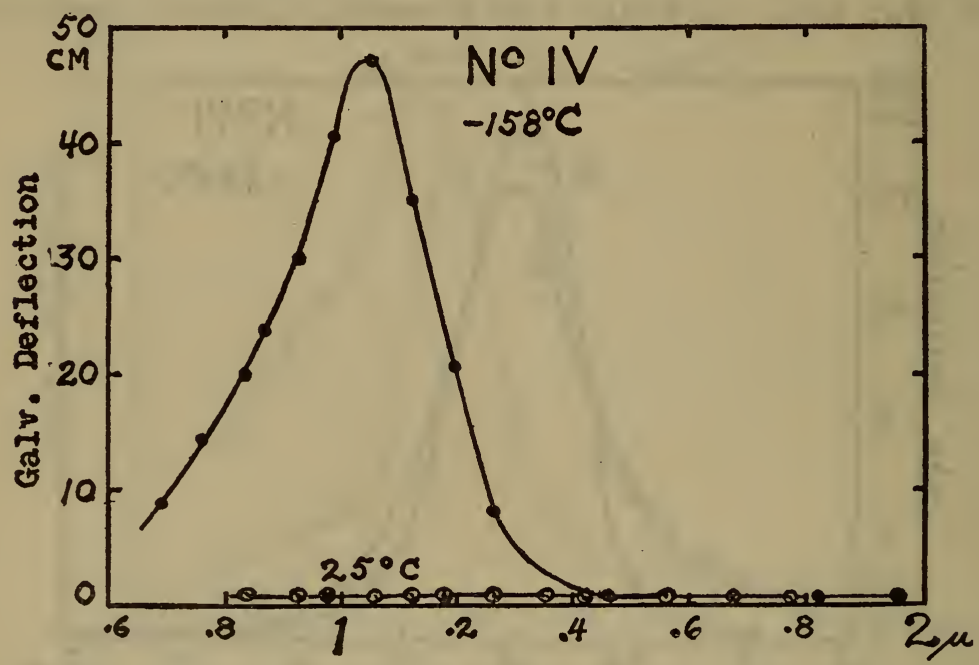

FIG. I6.-Photoelectrical sensitivity of an amorphous plate of a laboratory preparation of silver sulphide

trates a set of observations obtained by using unlimited exposure, which was from one to two minutes. The galvanometer deflections (amounting to about $5 \mathrm{~cm}$ at the maximum) are three times the scale indicated in Fig. I 7 .

\section{PHOTOELECTRICAL SENSITIVITY TESTS OF VARIOUS SUBSTANCES}

As already mentioned, it was of interest to determine whether substances which are quite insensitive, photoelectrically, become markedly sensitive at low temperatures. Spectral photoelectric sensitivity tests were made on galena, pyrites, jamesonite, and cylindrite. Previous tests ${ }^{10}$ showed that for high intensities 
cylindrite appeared photoelectrically sensitive. Case, ${ }^{11}$ using an arc light focussed upon the samples under test, found that galena and jamesonite were fairly sensitive to light.

\section{GALENA (PbS)}

The sample examined was a beautiful regular prism 12 by 3 by $3 \mathrm{~mm}$. The electrodes were of thin copper wire heated to the melting point, and quickly touched to the galena, which is melted, forming a strong juncture. Using the highest obtainable spectral

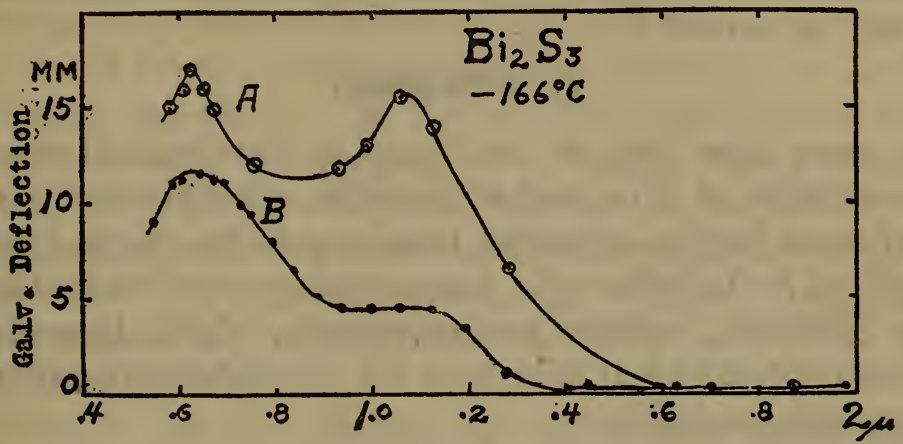

FIG. 17.-Spectral photoelectric sensitivity of bismuthinite

intensities, this sample of galena gave no indications of photoelectrical sensitivity either at $22^{\circ} \mathrm{C}$ or at $-160^{\circ} \mathrm{C}$.

\section{CYLINDRITE}

This is a lead-antimony tin mineral which occurs in cylindrical form. The sample examined was a beautiful cylinder about 2.5 $\mathrm{mm}$ in diameter and $\mathrm{I} 2 \mathrm{~mm}$ long. The copper lead wires were attached by heating them as was done with galena.

For the intensities obtainable this sample showed no photoelectrical sensitivity at $-160^{\circ} \mathrm{C}$.

\section{PYRITES $\left(\mathrm{FeS}_{2}\right)$}

The sample examined was a homogeneous fragment of a crystal about 9 by 3 by $3 \mathrm{~mm}$. The electrodes were fine, No. 36 copper wire wound in grooves filed around the ends of the crystal. No photoelectrical sensitivity was observed at $-160^{\circ} \mathrm{C}$. Previous tests, using high intensities, showed that this mineral is not sensitive at room temperatures. 
4. JAMESONITE (2 $\mathrm{Pb} \mathrm{S}$. $\mathrm{Sb}_{2} \mathrm{~S}_{3}$, SMITHSONIAN COLLECTION NO. 12500, FROM CORNWALL, ENGLAND)

The sample examined was a bundle of acicular crystals, io by 2.5 by $2 \mathrm{~mm}$. The electrodes were No. 36 copper wire tightly wound in grooves filed close to the ends of the crystal. This outfit was mounted securely upon a fiber base.

In the previous examination, using heterogeneous light, this mineral was found to be only slightly sensitive photoelectrically. The present tests were disappointing in that for the highest spectral intensities obtainable no evidence of photoelectrical sersitivity was found at $-160^{\circ} \mathrm{C}$.

\section{SUMMARY}

This paper gives data on the change in the electrical resistance of the sulphides of silver and of bismuth, when exposed to radiations of wave lengths extending from $0.6 \mu$ in the visible spectrum to about $3 \mu$ in the infra-red. Measurements were made also upon galena, cylindrite, pyrites, and jamesonite, which, however, did not show photoelectrical sensitivity for the highest spectral radiation intensities available.

In the sulphides of silver and of bismuth the radiations extending from $0.6 \mu$ to about I. $8 \mu$ produce a noticeable change in electrical conductivity.

The effect of temperature, of intensity of the exciting radiation, and of mechanical working upon photoelectrical sensitivity of silver sulphide, was investigated.

Both the natural mineral, acanthite and a laboratory preparation were examined. The latter material, which was hammered into a thin flexible plate, was found insensitive photoelectrically at room temperature. But at $-157^{\circ} \mathrm{C}$ a sharp maximum of photoelectrical sensitivity was observed for radiations of wave length $\lambda=\mathrm{I} .05 \mu$.

At room temperatures the natural crystalline material differs from other photoelectrically sensitive substances studied in that the photoelectric response becomes fatigued and, after an exposure of two to three seconds to light, the positive resistance change (galvanometer deflection) begins to be effective. For unlimited exposure the galvanometer deflection returns to about one-fifth of its maximum deflection. On removing the light stimulus the galvanometer gives a negative deflection, which in the course of a few minutes returns to the original zero scale reading. In other words, the change in resistance of the crystal, when exposed to 
radiation, is first negative and then positive, the resultant change being negative and roughly one-fifth the original change. At low temperatures, $-158^{\circ} \mathrm{C}$, this polarization phenomenon disappears, and the response to radiation is the same as that of other substances, for example, selenium and molybdenite. The spectral photoelectric sensitivity curve of crystalline silver sulphide, acanthite, at room temperature is conspicuous for its high sensitivity in the region of the spectrum extending from $0.6 \mu$ to I. $2 \mu$ followed by a maximum at about $I .35 \mu$. Lowering the temperature to $-15^{\circ} \mathrm{C}$ greatly increases the photoelectrical sensitivity of acanthite throughout the spectrum examined. The sensitivity curve is quite symmetrical with a maximum at $\mathrm{I} .2 \mu$

Increasing the intensity of the exciting radiations produces a more rapid response in the long wave lengths than in the short wave lengths, with a consequent shift of the maximum of the photoelectrical sensitivity curve toward the long wave lengths.

There is no simple law governing the variation in the photoelectric response in silver sulphide with variation in intensity of the radiation stimulus.

Mechanical working (hammering into a thin plate) appears to lower the intrinsic photoelectrical sensitivity of acanthite and changes the position of the maximum of spectral sensitivity.

A spectral photoelectric sensitivity curve of bismuthinite, $\mathrm{Bi}_{2} \mathrm{~S}_{3}$, was obtained at $-\mathrm{I} 66^{\circ} \mathrm{C}$. There are maxima of sensitivity at $0.64 \mu$ and $\mathrm{I} .08 \mu$, respectively.

WASHINGTON, March 4,'igig. 